\title{
LA ENSEÑANZA DE LA OFTALMOLOGÍA EN VALLADOLID
}

\author{
LÓPEZ DE LETONA C ${ }^{1}$
}

En la facultad de medicina de Valladolid se comenzó a impartir Oftalmolgía como asignatura independiente a partir de 1902; con anterioridad a esta fecha las explicaciones de nuestra materia se limitaban a algunas nociones incluidas en otras asignaturas, sobre todo la Patología Quirúrgica.

Pero hay otro dato curioso, en realidad hasta bien entrado el siglo XX no hubo un oftalmólogo que ocupase la cátedra y se ocupase de las explicaciones.

En 1902 inicia las enseñanzas oftalmológicas un profesor auxiliar de nuestra facultad, concretamente D. Fermín Pérez Macías. Estos profesores en aquellos años tenían una misión que hoy nos parecería cuanto menos curiosa ya que debían explicar aquellas asignaturas en las que no hubiese docente asignado, por este mmotivo nuestro protagonista se ocupó solo un curso de la Oftalmología ya que al siguiente fue enviado a impartir otra materia, concretamente Otorrino Laringología que debía estar por aquel entonces comenzando también a impartirse.

Los textos médicos oftalmológicos editados en castellano a finales del siglo XIX y principios del XX debían ser muy escasos, debemos citar Clinica y enfermedades de los ojos de Juan Santos Fernández editado en La Habana 1899, había también traducciones como el Manual Oftalmologico de J Micchell, vertido a nuestro idioma por Gastar de Sentiñon.

Después de Pérez Macías fue el catedrático de Ginecología D. Faustino Horcajo el encargado de las enseñanzas, pero fallece pronto y es entonces cuando se confían las enseñanzas oftalmológicas al nuevo titular de Ginecología D. Isidoro de la Villa y Sanz.

Evidentemente la Oftalmología por una serie de curiosas circunstancias se vinculaba a la Ginecología por estos años. Lo más probable es que Villa recurriese en sus explicaciones a otro de los escasos textos que no hemos citado anteriormente era el Tratado elemental de Oftalmología redactado por D. Sinforiano García Mansilla, que explicaba nuestra disciplina en Madrid.
Pero se dio otra curiosa circunstancia y es que Villa, que era por otro lado persona muy representativa de la vila valllisoletana (De hecho fue Alcalde, Rector y Presidente de la Academia de Medicina) fuese quien primero explicó Oftalmología a quien fue posteriormente primer oftalmólogo catedrático de esta asignatura: D. Emilio Díaz Caneja.

Esta situación duró hasta 1913, es entonces cuando Isidoro de la Villa renuncia a las explicaciones oftalmológicas a causa sobre todo de habérsele acumulado a la Ginecología el tener que impartir tambien Obstetricia.

El claustro de la facultad recibe entonces el ofrecimiento de ocuparse de los asuntos oftalmológicos de otro catedrático, concretamente D. Clodoaldo García Muñoz quien explicaba la asignatura denominada «Operaciones» equiparable a la actual Patología Quirúrgica.

Este profesor desempeña sus quehaceres hasta 1937, y debemos señalar que en el Hospital Clínico Provincial vinculado a la Facultad Médica existió a partir de 1920 una consulta de nuestra especialidad, no debía ser muy importante pero era la primera vez que comenzaba a funcionar.

Por otra parte el profesor García Muñoz practicaba algunas intervenciones oftálmicas llegando a redactar un texto de Oftalmología e incluso llegó a contar con un profesor auxíliar: D. José Cilleruelo Zamora, pero con todo, el nivel de la asignatura continuaba siendo muy modesto.

A la muerte de García Muñoz hay un período en que la Oftalmolgía debió ser impartida un curso por el catedrático de Anatomía y posteriormente por un auxiliar (El Dr. García Sinova), pero en 1947 se presenta en Valladolid D. Emilio Díaz Caneja Candanedo.

Nacido en Palencia en 1892 fallece en Santander en 1967. Realiza sus estudios médicos en Valladolid, y tras una breve estancia en Madrid con Manuel Márquez verificó el habitual viaje de ampliación de estudios en París. Retorna a su ciudad de origen y

\footnotetext{
1 IOBA. Valladolid. España.

E-mail: berta@ioba.med.uva.es
} 
pronto es nombrado jefe del servicio de Oftalmología de la Casa de Salud de Valdecilla que acababa de fundarse en Santander.

Es en 1947 cuando estaba ya próximo a cumpir los cincuenta años nuestro protagonista obtiene la cátedra de Oftalmología, estando un breve período de tiempo en Salamanca y luego en Valladolid.

Pero nunca abandonó su puesto asistencial en la capital cántabra, lo que no fue obstáculo para que fuese nombrado entre 1951 y 1957 Rector de la Universidad de Valladolid.

Durante sus años vallisoletanos Díaz Caneja contó con diversos colaboradores, de ellos el más desta- cado fue sin duda el Dr. D. José Lorente Talamas, hubo también una serie de jóvenes médicos que aspiraban a ser oftalmólogos que frecuentaron la clínica.

$\mathrm{Al}$ presentar Díaz Caneja su renuncia a su puesto docente, será Lorente quien se ocupe de la docencia hasta la llegada en 1963 de D. Nicolás Belmonte González que acababa de ganar la cátedra vallisoletana de Oftalmología.

La figura de Belmonte es conocida de sobra. Presidió la Sociedad Española de Oftalmología entre 1979 y 1983 y desarrolló en su cátedra una labor muy importante tanto en el campo asistencial como en el de la investigación. 